\title{
Model for determining and optimizing delivery performance in industrial systems
}

\author{
Flavia Fechete ${ }^{l,}$, and Anişor Nedelcu ${ }^{l}$ \\ ${ }^{1}$ Transilvania University of Brașov, Department of Manufacturing Engineering, Mihai Viteazu No.5, \\ Braşov, Romania.
}

\begin{abstract}
Performance means achieving organizational objectives regardless of their nature and variety, and even overcoming them. Improving performance is one of the major goals of any company. Achieving the global performance means not only obtaining the economic performance, it is a must to take into account other functions like: function of quality, delivery, costs and even the employees satisfaction. This paper aims to improve the delivery performance of an industrial system due to their very low results. The delivery performance took into account all categories of performance indicators, such as on time delivery, backlog efficiency or transport efficiency. The research was focused on optimizing the delivery performance of the industrial system, using linear programming. Modeling the delivery function using linear programming led to obtaining precise quantities to be produced and delivered each month by the industrial system in order to minimize their transport cost, satisfying their customers orders and to control their stock. The optimization led to a substantial improvement in all four performance indicators that concern deliveries.
\end{abstract}

\section{Introduction}

Industrial systems performance plays a crucial role for their survival and maintaining on the market, given the fierce competition which led to the disappearance from the market of those who are not progressing and therefore do not obtain high performance.

The current economic environment is no longer confined to strictly economic performance targets, it also requires a global vision of what the entity's performance really means.

Therefore it is no longer sufficient an exclusively economic approach to assess the financial performance of an organization, it requires a global vision that may relate to product and processes quality, entity's costs, on time delivery of their products or even to employees satisfaction. Delivery performance requires a special attention because it is closely related to customer satisfaction, the size of future orders, customer loyalty, and it may have a major implication on the revenue and expenses budget of the company.

\footnotetext{
* Corresponding author: fechete flavia@yahoo.com.
} 
In this regard it is imperative to meet the precise quantities to be produced so that delivery is made on time, according to the customer orders, and at the same time the delivery fits in the planned transport costs.

The present work aims to help the company to improve decision management system, to create a decision model that will contribute to improvement. The major objective of this paper is to create a model for the delivery performance of an industrial system, a model that will help the managers to make the best decisions on production optimization.

For this purpose, there will be used the linear programming to obtain the precise quantities to be produced and delivered each month by the industrial system in order to minimize their transport cost, satisfying their custormers orders and to control their stock.

Modeling and optimization techniques are used not only in the traditional supply chain management, but also in other functional areas of organizations as finance, accounting, marketing [1].

The problem of the delivery performance lies in the attention of many other researchers [2 - 4], though the delivery optimization focuses particularly on cost reduction, without taking into account other important factors.

In this regard, it was made a brief introduction to the theory of mathematical programming, following with a case study in order to develop the linear programming used to determine an optimal production program. The case study was conducted on an industrial system that produces and sells outer rings for cam follower rollers. The research was focused on delivering the products manufactured by the organization, it was intended to determine the optimal production program that satisfies customers orders and also minimizes the transport cost. Thus, it was determined the objective function and its constraints and using the linear programming module of the software Quantitative Management (QM), we were able to determine the amount of each product that must be manufactured in order to minimize the costs of delivery.

\section{Method}

The decision process involves evaluating several decisional alternatives based on economic indicators, in order to choose the optimal variant. For choosing the optimal decision it is necessary to hierarchy available variants, depending on the desired criteria. One of the most used methods in this regard it is economic modeling by linear programming.

Linear programming problem is within the general mathematical programming models and it is characterized by the fact that both the objective function and the constraints are expressed mathematically by linear functions [5].

The linear programming problem contains restrictions, as well as a criteria of "performance" to assess the effectiveness of each activity. Depending on the purpose, we can choose as a criterion of efficiency an indicator measuring the effort, one that measures the result or an indicator expressed as a ratio of result and effort (or effort and result) [6].

Maximum efficiency means minimizing the effort and maximizing the outcome and the optimal concept is defined in this case as a program that minimizes or maximizes an objective function and simultaneously satisfies all technical and economic restrictions [7].

In order to determine the optimal production program that satisfies customers orders and also minimizes the transport cost there will be used the following objective function $[1,6$, 8]:

$$
\min \left[\sum_{i=2}^{n}\left(\left(c_{i} \times x_{i}+c_{i}^{s} \times x_{i}^{s}+d \times s_{i}\right)+c_{1} \times x_{I}+c_{I}^{s} \times x_{I}^{s}\right)\right],
$$


With the following constraints:

$$
\begin{gathered}
\sum_{k=1}^{i}\left(x_{k}+x_{k}^{s}\right)-s_{i+1}=\sum_{k=1}^{i} R_{k}, \\
i=1,2, \ldots, n-1 \\
x_{n}+x_{n}^{s}+s_{n}=R_{n} \\
0 \leq x_{i} \leq y_{i}, i=1,2, \ldots, n \\
0 \leq x_{i}^{s} \leq y_{i}^{s}, i=1,2, \ldots, n \\
s_{i} \geq 0, i=1,2, \ldots, n, \text { where }
\end{gathered}
$$

$n$ - number of months;

$y_{i}, i=1,2, \ldots, n$ - monthly production volume achievable on normal program;

$y_{i}^{s}, i=1,2, \ldots, n$ - monthly production volume achievable overtime;

$c_{i}, i=1,2, \ldots, n$ - monthly cost of production on normal program;

$c_{i}^{s}, i=1,2, \ldots, n$ - monthly cost of production overtime;

$d$ - unit cost of storage;

$x_{i}, i=1,2, \ldots, n$ - quantities that must be monthly produced on normal program;

$x_{i}^{s}, i=1,2, \ldots, n$ - quantities that must be monthly produced overtime;

$s_{i}, i=1,2, \ldots, n-$ quantities that must be monthly stored.

In order to achieve the minimum costs of production and storage, variables $x_{i}, x_{i}^{S} s_{i}$ will be determined.

Determining the optimal production program is one of the major concerns of managers because it is closely related to the economic performance of the organization, deciding the success of the organization [9].

This paper presents below a study case of modeling and optimization the delivery performance of an industrial system by using linear programming. There is considered an industrial system that must sell their product during a period of 12 months, based on the customer orders. The paper objective is to analyze the current situation of delivery and to determine an optimal production program by using linear programming in order that shipping costs to be minimal.

\section{Results}

The delivery area is one of the most important aspect for each company, it may influence the customer behavior, the number of orders and the sales. The industrial system shows a major interest on this particular area, desiring to satisfy customer needs and minimizing their transportation expenses.

In order to identify the optimizing area, there will be first analyzed the main key indicators monitored in the delivery, as we proposed below. These indicators are:

\section{A. On-Time Delivery - OTD}

This indicator measures the percentage of all orders delivered by the requested delivery date, as indicated in the $\mathrm{PO} /$ contract during a defined period of time.

$$
O T D=\frac{N r c t}{N r c l} \times 100, \text { where }
$$

OTD $=$ On-Time Delivery;

$\mathrm{Nrc}_{\mathrm{t}}=$ Number of orders delivered at requested date;

$\mathrm{Nrc}_{1}=$ Number of orders. 


\section{B. Supplier Lead-Time Variability - SLT}

This indicator is the average of the absolute percentage differences (APD) between the supplier's forecasted lead time and the actual lead time for each order placed with the supplier. This indicator can be calculated for any supplier that supplies products to the requesting facility. It can be measured over any time period, but one year is typical; usually measured in days.

$$
\begin{gathered}
S L T=\frac{\sum A P D}{N r c} \\
A P D=\frac{I p r g-T r l}{T r l}, \text { where }
\end{gathered}
$$

SLT = Supplier Lead-Time Variability;

$\mathrm{APD}=$ Absolute percentage differences between the expected time delay in delivery of the supplier and real time delivery;

$\mathrm{Nr}_{\mathrm{c}}=$ Number of orders;

$\mathrm{I}_{\mathrm{prg}}=$ Expected delay;

$\mathrm{T}_{\mathrm{rl}}=$ Real time delivery.

C. Backlog efficiency - BE

This indicator measures the performance of the backlog comparing 2 consecutive months.

$$
B E=\frac{R l c}{R t} \times 100 \text {, where }
$$

$\mathrm{BE}=$ Backlog efficiency;

$\mathrm{R}_{\mathrm{lc}}=$ Total value of backlog delivered this month;

$\mathrm{R}_{\mathrm{t}}=$ Total value of backlog this month;.

D. Transport efficency - TE

$$
T E=\frac{C r t-C p t}{C r t} \times 100, \text { where }
$$

$\mathrm{TE}=$ Transport efficency;

$\mathrm{C}_{\mathrm{rt}}=$ Actual cost per transport;

$\mathrm{C}_{\mathrm{pt}}=$ Forecasted cost per transport.

Table 1 presents the results obtained from the industrial system for each performance indicator.

Table 1. Data used to calculate delivery indicators.

\begin{tabular}{|c|c|c|c|c|c|c|c|}
\hline Month & $\begin{array}{c}\text { Number } \\
\text { of orders } \\
\text { delivered } \\
\text { at } \\
\text { requested } \\
\text { date }\end{array}$ & $\begin{array}{c}\text { Number } \\
\text { of } \\
\text { orders }\end{array}$ & $\begin{array}{c}\text { Forecasted } \\
\text { cost per } \\
\text { transport } \\
\text { (euro) }\end{array}$ & $\begin{array}{c}\text { Actual cost } \\
\text { per } \\
\text { transport } \\
\text { (euro) }\end{array}$ & $\begin{array}{c}\text { Backlog } \\
\text { (Pieces) }\end{array}$ & $\begin{array}{c}\text { Real } \\
\text { time } \\
\text { delivery } \\
\text { (days) }\end{array}$ & $\begin{array}{c}\text { Expected } \\
\text { time } \\
\text { delay in } \\
\text { delivery } \\
\text { (days) }\end{array}$ \\
\hline Jan & 252 & 357 & 3500 & 14645,1 & 235805 & 6,5 & 5,5 \\
\hline Feb & 211 & 416 & 3500 & 18375,8 & 219434 & 6,8 & 6,2 \\
\hline Mar & 253 & 495 & 3500 & 7690,0 & 116117 & 6,9 & 7,1 \\
\hline April & 238 & 431 & 3500 & 7924,9 & 37888 & 7,0 & 8,9 \\
\hline May & 260 & 408 & 3500 & 6867,8 & 91333 & 6,5 & 6,3 \\
\hline
\end{tabular}




\begin{tabular}{|c|c|c|c|c|c|c|c|}
\hline June & 294 & 404 & 3500 & 3427,2 & 48175 & 6,3 & 6,1 \\
\hline July & 338 & 390 & 3500 & 2455,8 & 36523 & 6,0 & 5,9 \\
\hline Aug & 346 & 370 & 3500 & 6873,0 & 63181 & 5,9 & 5,4 \\
\hline Sept & 346 & 393 & 3500 & 6590,1 & 30351 & 5,7 & 4,9 \\
\hline Oct & 345 & 383 & 3500 & 2844,8 & 52786 & 5,9 & 6,1 \\
\hline Nov & 386 & 418 & 3500 & 2867,2 & 49517 & 5,5 & 4,7 \\
\hline Dec & 274 & 290 & 3500 & 1646,4 & 12379 & 13,0 & 12,3 \\
\hline
\end{tabular}

Using the data from Table 1 the delivery indicators were calculated; the evolution of the four performance indicators over the period of 12 months, it is presented in Table 2.

Table 2 Indicators evolution during months January-December.

\begin{tabular}{|c|c|c|c|c|}
\hline Month & OTD (\%) & SLT (\%) & BE (\%) & TE (\%) \\
\hline January & 70,588 & 94,714 & 90,75 & $-318,43$ \\
\hline February & 50,721 & 97,473 & 91,40 & $-425,02$ \\
\hline March & 51,111 & 99,408 & 95,76 & $-119,71$ \\
\hline April & 55,220 & 95,009 & 98,49 & $-126,42$ \\
\hline May & 63,725 & 99,202 & 96,68 & $-96,22$ \\
\hline June & 72,772 & 99,295 & 98,16 & 2,08 \\
\hline July & 86,667 & 99,374 & 98,64 & 29,83 \\
\hline August & 93,514 & 97,492 & 97,54 & $-96,37$ \\
\hline September & 88,041 & 95,761 & 98,76 & $-88,29$ \\
\hline October & 90,078 & 99,328 & 98,24 & 18,72 \\
\hline November & 92,344 & 95,981 & 98,21 & 18,08 \\
\hline December & 94,483 & 98,055 & 99,45 & 52,96 \\
\hline
\end{tabular}

As it can be seen, the risk is on having an efficient transport, namely, that the delay in delivery of the ordered pieces increases the transportation expenses for the backlog products. Indicators evolution and graphic analysis is provided in Fig. 1.

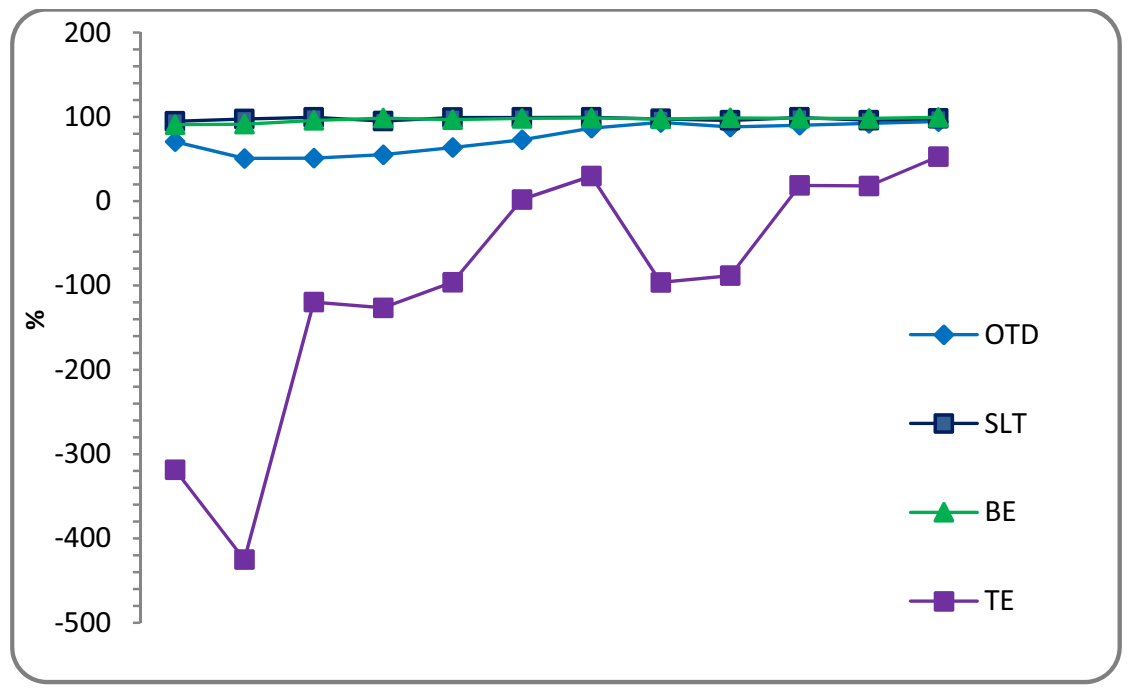

Fig.1. Delivery indicators: OTD, SLT, BE and TE. 
This paper aims to optimize the delivery area of the analyzed industrial company, which is a major problem for this company, owed to backlog in delivery and significant transportation costs because undelivered parts incur much higher costs.

Thus, knowing the amount of pieces that will be delivered for the next 12 months, according to the customer orders, the production capacity for each month, and the cost per piece, there will be determined the optimal production by using linear programming in order that shipping costs to be minimal.

The industrial system spends 25 euro/min for getting a piece of the outer ring and the cost of delivery of the backlog on a special transport is 5 euro/piece.

Annotations:

$\mathrm{x}_{1}, \mathrm{X}_{2}, \mathrm{x}_{3}, \ldots, \mathrm{x}_{12}=$ The quantity of parts to be delivered in 12 months.

It will thus obtain the following restrictions:

$$
\left\{\begin{array}{c}
x_{i}>0, \quad i=\overline{1,12} \\
x_{1} \geq 2548556 \\
x_{2}+\left(x_{1}-2548556\right) \geq 2550855 \\
x_{3}+\left(x_{1}+x_{2}-5099411\right) \geq 2735389 \\
x_{4}+\left(x_{1}+x_{2}+x_{3}-7834800\right) \geq 2503787 \\
x_{5}+\left(x_{1}+\ldots+x_{4}-10338587\right) \geq 2750643 \\
x_{6}+\left(x_{1}+\ldots+x_{5}-13089230\right) \geq 2624632 \\
x_{7}+\left(x_{1}+\ldots+x_{6}-15713862\right) \geq 2682187 \\
x_{8}+\left(x_{1}+\ldots+x_{7}-18396049\right) \geq 2563748 \\
x_{9}+\left(x_{1}+\ldots+x_{8}-20959797\right) \geq 2451276 \\
x_{10}+\left(x_{1}+\ldots+x_{9}-23411073\right) \geq 2992994 \\
x_{11}+\left(x_{1}+\ldots+x_{10}-26404067\right) \geq 2761731 \\
x_{12}+\left(x_{1}+\ldots+x_{11}-29165798\right) \geq 2258991 \\
x_{1} \leq 2700000 \\
x_{2} \leq 2500000 \\
x_{3} \leq 2700000 \\
x_{4} \leq 2800000 \\
x_{5} \leq 2800000 \\
x_{6} \leq 2700000 \\
x_{7} \leq 2800000 \\
x_{8} \leq 3000000 \\
x_{9} \leq 2800000 \\
x_{10} \leq 3000000 \\
x_{11} \leq 2800000 \\
x_{12} \leq 2100000 \\
\end{array}\right.
$$

The data used to optimize the delivery performance are presented in Table 3: 
Table 3. Required data for the optimization process.

\begin{tabular}{|c|c|c|c|}
\hline Month & $\begin{array}{c}\text { Customer orders } \\
\text { (pieces) }\end{array}$ & $\begin{array}{c}\text { Production capacity } \\
\text { (pieces) }\end{array}$ & $\begin{array}{c}\text { Expenses } \\
\text { (euro/min) }\end{array}$ \\
\hline January & 2548556 & 2700000 & 25 \\
\hline February & 2550855 & 2500000 & 25 \\
\hline March & 2735389 & 2700000 & 25 \\
\hline April & 2503787 & 2800000 & 25 \\
\hline May & 2750643 & 2800000 & 25 \\
\hline June & 2624632 & 2700000 & 25 \\
\hline July & 2682187 & 2800000 & 25 \\
\hline August & 2563748 & 3000000 & 25 \\
\hline September & 2451276 & 2800000 & 25 \\
\hline October & 2992994 & 3000000 & 25 \\
\hline November & 2761731 & 2800000 & 25 \\
\hline December & 2258991 & 2100000 & 25 \\
\hline
\end{tabular}

Considering the cost of production and transport, the objective function becomes:

$$
\begin{aligned}
& f(x)=25 x_{1}+25 x_{2}+\ldots+25 x_{12}+5 \times\left(x_{1}-2548556\right)+5 \times\left(x_{1}+x_{2}-5099411\right)+ \\
& 5 \times\left(x_{1}+x_{2}+x_{3}-7834800\right)+5 \times\left(x_{1}+\cdots+x_{4}-10338587\right)+5 \times\left(x_{1}+\cdots+x_{5}-\right. \\
& 13089230)+5 \times\left(x_{1}+\cdots+x_{6}-15713862\right)+5 \times\left(x_{1}+\cdots+x_{7}-18396049\right)+5 \times \\
& \left(x_{1}+\cdots+x_{8}-20959797\right)+5 \times\left(x_{1}+\cdots+x_{9}-23411073\right)+5 \times\left(x_{1}+\cdots+x_{10}-\right. \\
& 26404067)+5 \times\left(x_{1}+\cdots+x_{11}-29165798\right) .
\end{aligned}
$$

The minimum of the function:

$$
\begin{aligned}
& f(x)=25 x_{1}+25 x_{2}+\ldots+25 x_{12}+55 x_{1}+50 x_{2}+45 x_{3}+40 x_{4}+35 x_{5}+30 x_{6}+25 x_{7}+ \\
& 20 x_{8}+15 x_{9}+10 x_{10}+5 x_{11}-172961230 .
\end{aligned}
$$

The final objective function will be:

$$
\begin{aligned}
& \min f(x)=80 x_{1}+75 x_{2}+70 x_{3}+65 x_{4}+60 x_{5}+55 x_{6}+50 x_{7}+45 x_{8}+40 x_{9}+35 x_{10}+ \\
& 30 x_{11}+25 x_{12}-172961230
\end{aligned}
$$

To simplify calculations, data were inserted in the software Quantitative Management (QM) as shown in Fig. 2. 


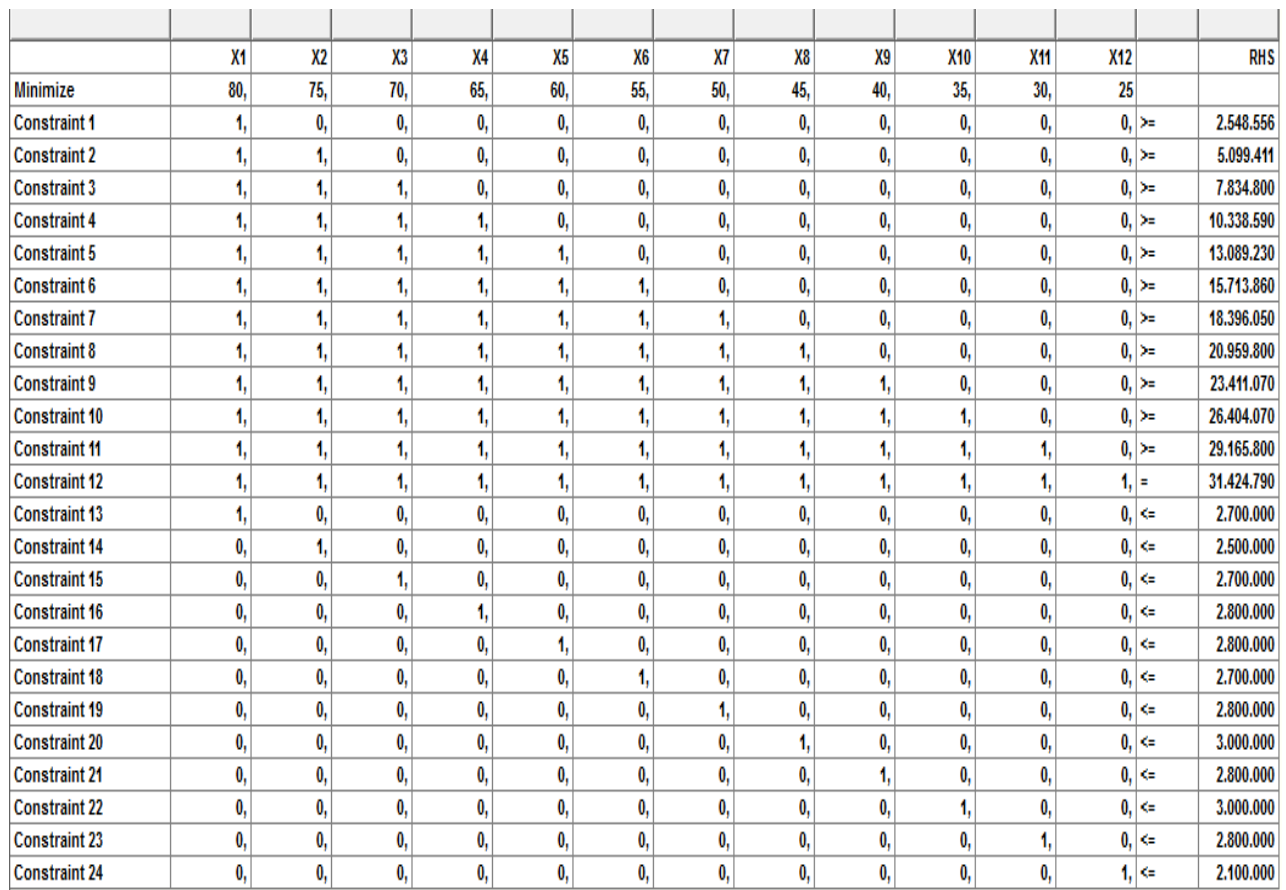

Fig. 2. Objective function and restrictions introduced in module Linear Programming of QM.

By solving the objective function in the QM program, it will obtain the results presented in Fig. 3 and in Fig.4.

\begin{tabular}{|c|c|c|c|c|c|c|c|c|c|c|c|c|c|c|}
\hline & $\mathrm{X}_{1}$ & $\mathrm{X} 2$ & X3 & $x_{4}$ & X5 & $x_{6}$ & $x 7$ & $x_{8}$ & x9 & $\mathrm{X} 10$ & $\mathrm{X} 11$ & $\mathrm{X} 12$ & & RHS \\
\hline Minimize & 80, & 75 , & 70 & 65 & 60 , & 55, & 50, & 45, & 40, & 35 , & 30 , & 25 , & & \\
\hline Constraint 1 & 1, & 0 , & 0 , & 0 , & 0 , & 0 , & 0 , & 0 , & 0 , & 0, & 0 , & 0 , & $x=$ & 2.548.556, \\
\hline Constraint 2 & 1, & 1, & 0 , & 0 , & 0 , & 0, & 0 , & 0 , & 0, & 0 , & 0, & 0 , & $x=$ & 5.099.411, \\
\hline Constraint 3 & 1, & 1, & 1, & 0 , & 0 , & 0, & 0, & 0 , & 0 , & 0, & 0 , & 0 , & $>=$ & 7.834.800, \\
\hline Constraint 4 & 1, & 1, & 1, & 1, & 0, & 0 , & 0 , & 0 , & 0 , & 0, & 0 , & 0, & $x=$ & 10.338.590, \\
\hline Constraint 5 & 1, & 1, & 1, & 1, & 1, & 0 , & 0 , & 0 , & 0 & 0, & 0 & 0, & $x=$ & 13.089.230, \\
\hline Constraint 6 & 1, & 1, & 1, & 1, & 1, & 1, & 0 , & 0 , & 0 , & 0 , & 0 , & 0, & $>=$ & 15.713.860, \\
\hline Constraint 7 & 1, & 1, & 1, & 1, & 1, & 1, & 1, & 0 , & 0, & 0, & 0, & 0, & $x=$ & 18.396.050, \\
\hline Constraint 8 & 1, & 1, & 1, & 1, & 1, & 1, & 1, & 1, & 0 , & 0 , & 0 , & 0, & $x=$ & 20.959.800, \\
\hline Constraint 9 & 1, & 1, & 1, & 1, & 1, & 1, & 1, & 1, & 1, & 0, & 0 , & 0, & $y=$ & 23.411.070, \\
\hline Constraint 10 & 1, & 1, & 1, & 1, & 1, & 1, & 1 , & 1, & 1, & 1, & 0, & 0 , & $x=$ & 26.404.070, \\
\hline Constraint 11 & 1, & 1, & 1, & 1, & 1, & 1, & 1, & 1, & 1, & 1, & 1, & 0 , & $x=$ & 29.165.800, \\
\hline Constraint 12 & 1, & 1, & 1, & 1, & 1, & 1, & 1, & 1, & 1, & 1, & 1, & 1, & $=$ & 31.424.790, \\
\hline Constraint 13 & 1, & 0 , & 0, & 0 , & 0 , & 0 , & 0, & 0 , & 0 , & 0, & 0 , & 0 , & $<=$ & 2.700 .000 \\
\hline Constraint 14 & 0 , & 1, & 0, & 0 , & 0 , & 0, & 0 , & 0 , & 0, & 0, & 0, & 0 , & $<$ & 2.500 .000 , \\
\hline Constraint 15 & 0 , & 0 , & 1, & 0 , & 0 , & 0 , & 0 , & 0 , & 0 , & 0, & 0 , & 0, & $<=$ & 2.700 .000 , \\
\hline Constraint 16 & 0 , & 0 , & 0, & 1, & 0 , & 0 , & 0 , & 0 , & 0 , & 0 , & 0 , & 0, & $\Leftrightarrow$ & 2.800 .000 , \\
\hline Constraint 17 & 0 , & 0 , & 0 , & 0 , & 1, & 0, & 0 , & 0 , & 0 , & 0 , & 0 , & 0 , & $\ll$ & 2.800 .000 , \\
\hline Constraint 18 & 0 , & 0 , & 0, & 0 , & 0 , & 1, & 0 , & 0 , & 0 , & 0 , & 0 , & 0, & $<$ & 2.700 .000 \\
\hline Constraint 19 & 0 , & 0, & 0 & 0 & 0 & 0 , & 1, & 0 , & 0 , & 0, & 0 , & 0, & $<=$ & 2.800 .000 , \\
\hline Constraint 20 & 0 , & 0 , & 0 , & 0 , & 0 , & 0, & 0 , & 1, & 0 , & 0, & 0 , & 0, & $<$ & 3.000 .000 , \\
\hline Constraint 21 & 0 , & 0, & 0, & 0 & 0 , & 0 , & 0 , & 0 , & 1, & 0, & 0, & 0 , & $<$ & 2.800 .000 , \\
\hline Constraint 22 & 0 , & 0 , & 0 , & 0 , & 0 , & 0 , & 0 , & 0 , & 0 , & 1, & 0 , & 0, & $<=$ & 3.000 .000 , \\
\hline Constraint 23 & 0 , & 0 , & 0 & 0 & 0 , & 0 , & 0, & 0 , & 0 , & 0 , & 1, & 0 , & $<=$ & 2.800 .000 , \\
\hline Constraint 24 & 0 , & 0, & 0, & 0, & 0, & 0, & 0 , & 0 , & 0, & 0, & 0, & 1, & $<=$ & 2.100 .000 \\
\hline Solution-> & 2.634 .800 & 2.500 .000 & 2.700 .000 & 2.503.790, & 2.750 .640 & 2.624 .630 & 2.682.190, & 2.563.750, & 2.564.990, & 3.000 .000 & 2.800 .000 & 2.100 .000 & & $\$ 1.653 .001 .250$, \\
\hline
\end{tabular}

Fig. 3. The optimized solutions obtained by solving the objective function. 
As it can be seen in Fig. 4, to obtain optimal costs, the industrial company should deliver, respecting customer requirements and production capabilities, the following quantities: in January 2634800 pieces, in February 2500 000, in March: 2700000 pieces, in April 2503790 million pieces, May: 2750640 units, in June 2624630 units, in July 2682190 units, in August: 2563750 pieces, in September 2564 990, October 3000000 units, in November: 2800000 units, and at the end of the year, in December, 2100000 pieces.

\begin{tabular}{|l|r|r|r|r|r}
\hline Variable & Value & Reduced & Original & Lower & Upper \\
\hline X1 & 2.634 .800$, & 0, & 80, & 75, & Infinity \\
\hline X3 & 2.500 .000$, & 0, & 75, & -Infinity & 80, \\
\hline X4 & 2.700 .000$, & 0, & 70, & -Infinity & 80, \\
\hline X5 & 2.503 .790$, & 0, & 65, & 60, & 80, \\
\hline X6 & 2.750 .640$, & 0, & 60, & 55, & 65, \\
X7 & 2.624 .630$, & 0, & 55, & 50, & 60, \\
\hline X8 & 2.682 .190$, & 0, & 50, & 45, & 55, \\
\hline X9 & 2.563 .750$, & 0, & 45, & 40, & 50, \\
\hline X10 & 2.564 .990 & 0, & 40, & 35, & 45, \\
\hline X11 & 3.000 .000$, & 0, & 35, & -Infinity & 40, \\
\hline X12 & 2.800 .000$, & 0, & 30, & -Infinity & 40, \\
\hline
\end{tabular}

Fig. 4. The optimal quantities to be delivered by the industrial company.

After applying the new optimized variants for delivery it can be seen that the optimization led to a substantial improvement in all performance indicators that concern deliveries.

After optimization, the performance indicators OTD, SLT, BE and TE have values between 94 and $100 \%$ (Fig.5), which means that deliveries are made according to the clients needs, without additional expenditure of special transport.

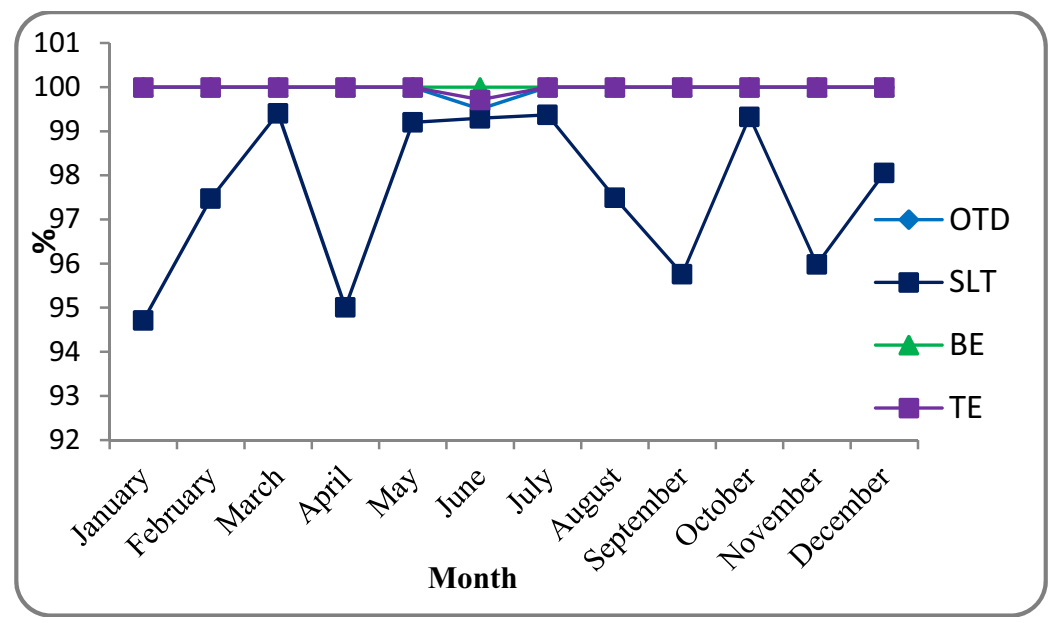

Fig. 5. Delivery indicators after optimization.

\section{Conclusions}

The main objective of business process modeling is to optimize decision-making process, as a determining factor in the transition from experience, intuition complex, to a scientific approach based on information-reasoning. Economic modeling process enables the 
manager making the best decision, giving it multiple ways to make an efficient agreement between human, material, financial with the main objectives of the organization.

This paper objective is to help managers to improve the delivery performance of the organization by determining and implementing an optimal production program. Modeling a manufacturing program using the QM software led to obtaining precise quantities to be produced and delivered each month by the industrial system in order to minimize their transport cost, satisfying their custormers orders and to control their stock.

Future research will focus on multi-criteria modeling methods, namely the multidimensional linear programming that allows to use the objective function as a utility function that will combine both criteria of maximizing profits and minimizing costs.

\section{References}

1. D. Lixandroiu, Economic processes modeling (Transilvania University Publishing House, Braşov, 2012).

2. A. Guiffrida, R. Nagi, Int. J. Production Economics 102, 22-36 (2006).

3. A. Gunasekarana, C.Patelb, R.E.McGaugheyc, Int. J. Production Economics 87, 333347 (2004).

4. H. Shina, W.C.Bentonb, M.Junc, Comp \& Op R 36, 2462 - 2471 (2009).

5. M. Beldiga, Sci.Jur.S.Univ.Mold 7, 34-39 (2012).

6. A .Nedelcu, Technology and flexible manufacturing systems (Lux Libris Publishing House, Brasov, 2000).

7. C. Anghelache, Modeling and simulation of decision-making processes - lecture notes (Artifex, Bucuresti, 2003).

8. M. Andrasiu, Multi-criterion Decision Methods, (Tehnica Publishing House, Bucuresti, 1986).

9. A. Rusu, Operational Research (Iasi, 2007). 